\title{
Direct secretory effect of interleukin-1 via type I receptors in human colonic mucous epithelial cells (HT29-Cl.16E)
}

\author{
A Jarry, G Vallette, J-E Branka, C Laboisse
}

\begin{abstract}
The stable differentiated human colonic epithelial cell line, HT29-Cl.16E, was used to study the effects of interleukin-1 (IL-1) on mucin exocytosis. The main findings include: (a) IL-1 stimulated a rapid release of mucin from filter grown HT29Cl.16E cells, this effect being dose related; (b) this secretory effect was abolished in the presence of the blocking monoclonal antibody M4 specific for IL-1 receptors type I, showing that IL-1 receptors type I mediated IL-1 action; (c) experiments based on chamber cultures showed that these receptors were located on the basolateral membranes of $\mathrm{HT} 29-\mathrm{Cl} .16 \mathrm{E}$ cells; (d) finally, mRNA for IL-1 receptors type I were detected by reverse transcriptasepolymerase chain reaction in these cells. To extend these findings to the in vivo situation, the rapid stimulatory effect of IL-1 on mucin exocytosis may contribute to the wash out of noxious agents during mucosal inflammation.
\end{abstract}

(Gut 1996; 38: 240-242)

Keywords: colonic cell line (human), cytokine regulation, interleukin-1, interleukin-1 receptors, mucin secretion.

Interleukin-1 (IL-1) is a proinflammatory cytokine, present in the gastrointestinal mucosa, where it is released by lamina propria activated immune cells during inflammation. ${ }^{1}$ IL- 1 has been found to induce mucin release from explant cultures of mouse duodenum, ${ }^{2}$ this finding suggesting that IL-1 may reinforce the defence of the intestinal mucosa during inflammation. The secretory effect of IL-1 seen in mucosal explants, which are the site of many cellular interactions, could be the result either of a direct effect of IL-1 on intestinal epithelial mucous cells or of an indirect effect through the release of a secretagogue secreted by another cell type. Finally, both direct and indirect pathways may account for the secretagogue action of this cytokine.

On the one hand the indirect pathway is supported by recent in vivo experiments in the rat showing that IL-1 mediated colonic hypersecretion entails mast cell degranulation. ${ }^{3}$ On the other hand, the recent finding of IL-1 receptors type I on the rat epithelial intestinal cell line IEC-18 strongly supports the hypothesis of a direct action of IL-1 on epithelial cells. ${ }^{4}$ As IEC-18 cells are considered undifferentiated, ${ }^{4}$ however, they are not suitable for assigning a biological role to the IL-1 receptors type I present at the epithelial cell surface.

The ideal system for (a) providing unambiguous evidence that a direct pathway is implicated in the secretory effect of IL-1 on intestinal epithelial mucous cells, the so called goblet cells, and (b) deciphering this pathway, would be a pure population of epithelial mucous cells maintained in culture. An in vitro model having these characteristics is the so called HT29-Cl.16E cell line, a human homogeneous colonic epithelial goblet cell line, which is a clonal derivative of HT29 cells. $^{5}$ Recent studies based on this cell line used in combination with a sensitive and specific assay for secretory mucins ${ }^{6}$ have clearly shown that HT29-Cl.16E cells have in vitro the same functional characteristics as those of goblet cells in vivo. ${ }^{6} 7$

Here we show that IL-1 induces a rapid and dose related exocytotic release of mucins from HT29-Cl.6E cells, and that this effect is mediated by IL- 1 receptors type I located at the basolateral surface of these cells.

\section{Methods}

\section{Cell culture}

HT29-Cl.16E cells were seeded on porous nitrocellulose filters (Millipore filters $\mathrm{HAHY}$, porosity $0.45 \mu \mathrm{m} ; 2 \times 10^{6}$ cells per filter) as previously described. ${ }^{6}$ For the experiments aimed at determining the location of IL-1 membrane receptors, HT29-Cl.16E cells were plated on filters mounted in chamber cultures (Millicell culture plate inserts, 0.45 $\mu \mathrm{m}$ porosity, Millipore, $1 \cdot 2 \times 10^{6}$ cells per chamber), which delineate an apical (luminal) and a basolateral (serosal) reservoir. The cells were cultured in Dulbecco's modified medium (DMEM, Gibco, Paris, France) supplemented with $10 \%$ heat inactivated fetal calf serum (FCS, Gibco). HT29-Cl.16E cells form at confluency homogeneous monolayers of differentiated goblet cells, secreting a mucus gel in the culture medium. ${ }^{5}$

Stimulation of mucin exocytosis by $I L-1$ and measurement of secretory mucins

Filter grown HT29-Cl.16E cells were metabolically labelled for 24 hours with $4 \mu \mathrm{Ci} / \mathrm{ml}$ of $\mathrm{D}\left[6-{ }^{3} \mathrm{H}\right]$-glucosamine as previously reported. ${ }^{6}$ The cells were then rinsed and incubated for 15 minutes in the presence of IL-1. The incubation medium was then removed by a pipette and the monolayer was rinsed with the 
spent medium to remove adherent mucins. The collected medium was then dialysed against distilled water, and mucins were measured as ${ }^{3} \mathrm{H}$-labelled macromolecules trapped at the stacker-gel/interface of 3\% polyacrylamide gels, as previously described. ${ }^{6}$

$R N A$ extraction and reverse transcriptasepolymerase chain reaction ( $R T-P C R$ )

Total cellular RNA was extracted from HT29Cl.16E cells with RNAzol (Bioprobe, Montreuil, France), in a one step procedure according to the manufacturer's instructions. Ten $\mu \mathrm{g}$ of total RNA was reverse transcribed using oligod $\mathrm{T}_{12-18}$ primer (Clontech). Five $\mu \mathrm{l}$ of the resulting cDNA was submitted to PCR using specific primers for IL-1 receptors type I from Clontech (sense: 5'-ACA CAT GGT ATA GAT GCA GC-3', and antisense: 5'-TTC CAA GAC CTC AGG CAA GA-3'). Amplification was performed for 30 cycles in an automated thermal cycler (Hybaid) (denaturation one minute at $94^{\circ} \mathrm{C}$, annealing one minute at $60^{\circ} \mathrm{C}$, extension two minutes at $72^{\circ} \mathrm{C}$ ). Appropriate controls were done for each PCR reaction: positive control (control cDNA, Clontech), negative controls (one without RNA, and one without RT to rule out any contamination by genomic DNA). PCR products were run on a $1.6 \%$ agarose gel, visualised after ethidium bromide staining, blotted onto nitrocellulose filters (Schleicher and Schuell), and hybridised with a ${ }^{32} \mathrm{P}$ labelled human IL-1 receptor type I cDNA probe, using a standard Southern blot procedure.

\section{Reagents}

The ${ }^{3} \mathrm{H}$-glucosamine used was from Amersham, Paris, France (specific activity 20 to 40 $\mathrm{Ci} / \mathrm{mmol}$ ). IL-1 $\beta$, referred to as IL-1 if not otherwise stated, was from $R \& D$ Systems (Oxford, England), IL-1 $\alpha$ from BoehringerMannheim (Meylan, France). The blocking monoclonal antibody M4 directed to IL-1 receptors type $\mathrm{I}$, and the $\mathrm{cDNA}$ probe specific for IL-1 receptors type I were kind gifts from Dr Sims (Immunex Corporation, Seattle). Specificity of the M4 antibody has been assessed by immunoprecipitation of metabolically labelled or ${ }^{125}$ I-IL-1 $\beta$ cross linked labelled cell lysates, ${ }^{89}$ showing unambiguously that only the $80 \mathrm{kDa}$ form (IL-1 receptors type I) was recognised by this antibody.

\section{Results}

The addition of IL-1 to filter grown monolayers of HT29-Cl.16E cells elicited a rapid stimulation of ${ }^{3} \mathrm{H}$-mucin release within the 15 minute incubation. This secretory effect was dose related for both IL- $1 \alpha$ and IL-1 $\beta$ (Fig 1 ). At its maximal effective concentration $\left(10^{-9} \mathrm{M}\right)$, IL-1 elicited a $1 \cdot 7$ to twofold stimulation of ${ }^{3} \mathrm{H}$-mucin release.

The recent availability of monoclonal antibodies that specifically block IL-1 receptors type $I_{,}^{89}$ makes it possible to test the

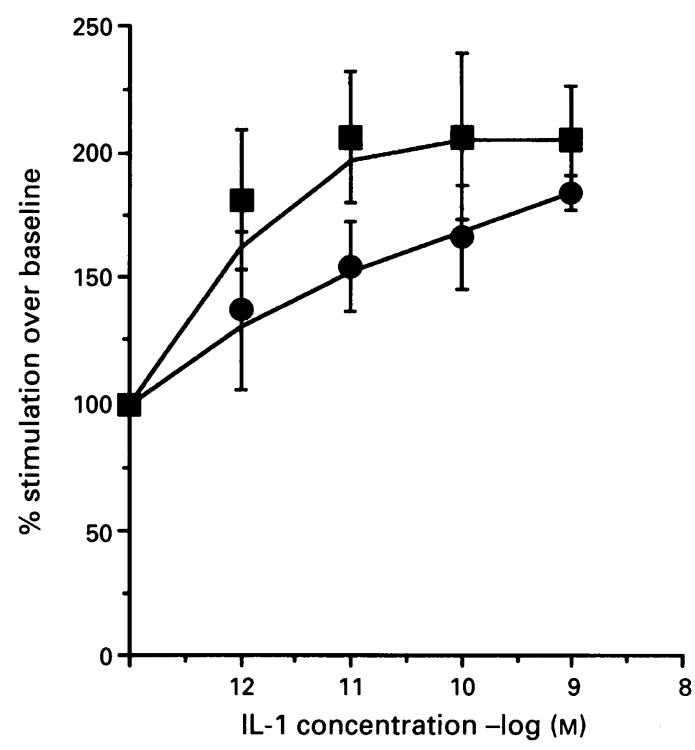

Figure 1: Dose related effect of IL-1 on HT29-Cl.16E mucin exocytosis. Filter grown HT29-Cl. $16 E$ monolayers were labelled with ${ }^{3} \mathrm{H}$-glucosamine for 24 hours and then challenged for 15 minutes with either IL-1 $\beta$ (⿴) or IL-1 $\alpha$ (๑). ${ }^{3} \mathrm{H}$-mucins were assessed as described in Methods. The results are expressed as per cent stimulation of mucin release over baseline secretion. Values are means (SEM) of nine monolayers from three different experiments, for each cytokine.

implication of these receptors in IL-1 action on HT29-Cl.16E cells. To this end, HT29Cl.16E monolayers were preincubated for 90 minutes in the presence of $\mathrm{M} 4(5 \mu \mathrm{g} / \mathrm{ml})$ and then challenged with IL-1 for 15 minutes. In such conditions, the stimulatory effect of IL-1 was completely abolished by M4 antibody (Fig 2). The finding that the exocytotic

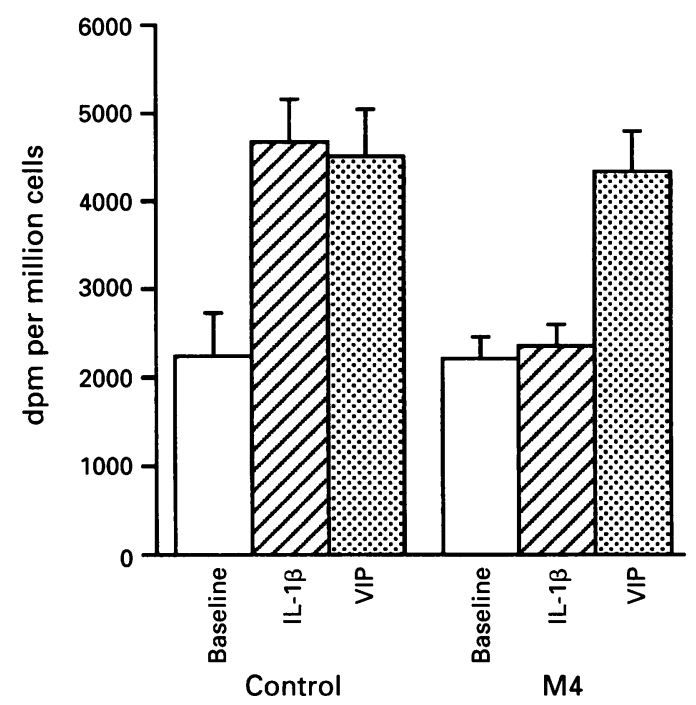

Figure 2: Inhibition of IL-1 induced secretory response by $M 4$ monoclonal antibody directed to IL-1 receptor type I. HT29-Cl.16E monolayers were pre-treated (M4) or not (Control), for 90 minutes with $5 \mu \mathrm{g} / \mathrm{ml} \mathrm{M4}$ antibody, before being challenged for 15 minutes with $10^{-10} \mathrm{M} \mathrm{IL}-1 \beta$ or with $10^{-6} \mathrm{M}$ vasoactive intestinal peptide (VIP). ${ }^{3} \mathrm{H}$-mucins were assessed as described in Methods. The results are expressed as dpm per million cells. The stimulation of the exocytotic response elicited by $I L-1 \beta$ and VIP was statistically significant compared with baseline secretion $(p<0.001)$, and the inhibitory effect of M4 on $I L-1 \beta$ stimulatory effect was statistically significant $(p=0.004$ between $I L-1 \beta$ and $I L-1 \beta+M 4)$. Values are means (SEM) of nine monolayers for IL-1 and $I L-1+M 4$ (three independent experiments), and of three monolayers for VIP and VIP +M4. 
response to vasoactive intestinal peptide remained unchanged in the presence of M4 antibody (Fig 2) is a clear indication that the antibody added to the incubation medium did not exert in itself a non-specific inhibition of the exocytotic response.

As several studies have shown that most neuroendocrine receptors are restricted to the basolateral membrane facing the internal medium, it was important to examine the location of the receptors for the cytokine IL-1. For this reason, HT29-Cl.16E monolayers were cultured in chambers, which permits the incubation of the cytokine either at the apical (mucosal) or basolateral (serosal) pole of the cells. In such conditions, IL-1 stimulated ${ }^{3} \mathrm{H}$-mucin exocytosis when added to the basolateral reservoir mean (SEM) 153\% (13\%) of baseline secretion, $n=4$ monolayers), whereas it had no effect when added to the apical reservoir $(97 \%(5 \%)$ of baseline secretion, $n=4$ monolayers).

Finally, the presence of mRNA coding for IL-1 receptors type I was determined using RT-PCR. Figure 3 shows a representative experiment where RT-PCR performed on RNA extracted from confluent HT29-Cl.16E monolayers generated a $300 \mathrm{bp}$ product (lane 5 ), the specificity of which was confirmed by Southern blot analysis, using an IL-1 receptor type I cDNA probe. Figure 3 also shows that IL-1 receptors type I are not only present in the mucous secreting cells HT29-Cl.16E, but also in the parental cell line HT29 (lane 4) and in another clonal derivative, HT29-Cl.19A (lane 3), which is an electrolyte secreting cell line. ${ }^{5}$

\section{Discussion}

This study based on a human cell line extends the finding in a mouse model that IL-1 is able to induce mucin hypersecretion from the intestinal mucosa. ${ }^{2}$ In addition, this study provides the first unambiguous demonstration that IL-1 directly stimulates mucin exocytosis from colonic epithelial cells via IL-1 receptors type I located at their basolateral membranes.

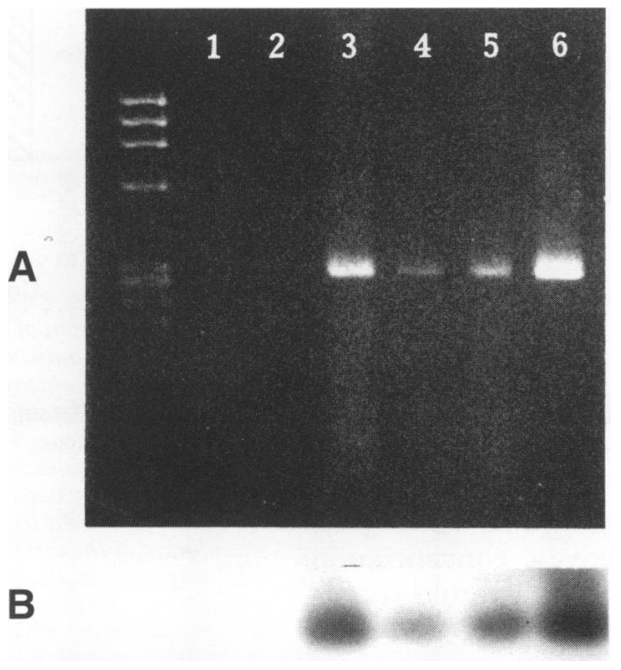

Our experimental evidence includes (a) the finding that IL-1 triggers a dose dependent exocytotic response from a pure population of mucous cells in culture devoid of any other contaminating cell type, (b) the strong inhibitory action of blocking monoclonal antibodies specific for IL-1 receptors type I on the stimulatory effect of IL-1, and (c) the polarised action of IL-1.

Intestinal goblet cells are structurally polarised epithelial cells whose main function is to protect the intestinal mucosa by secreting a mucus gel at their apical pole serving to protect the mucosa and to wash out pathogens present in the intestinal lumen. A number of studies based on in vivo or in vitro models have shown that the mucin exocytotic function of goblet cells may be modulated by various agents including neuroendocrine mediators acting via specific receptors located at the basolateral surface of the cells. ${ }^{10}$ In addition to being in itself a secretagogue for goblet cells, IL-1 may bring a number of soluble mediators (neurocrine and inflammatory mediators) in the vicinity of epithelial cells through mast cell degranulation and nervous stimulation. It can be thus suggested that epithelial goblet cells may be the target for potentiating interactions between IL-1 and some neurocrine agents or inflammatory mediators on mucus secretion. Further experiments are needed to explore this hypothesis.

Finally, the finding of a direct control of mucin exocytosis by immune mediators reveals new possibilities for the pharmacological manipulation of an epithelial important secretory function.

The authors are grateful to Dr Sims (Immunex Corporation, Seattle) for the kind gifts of M4 antibody and IL-1 receptor type I cDNA probe. This work was supported by the Association Association pour la Recherche sur le Cancer (ARC), and the Fondation pour la Recherche Médicale (FRM).

1 Sartor RB. Cytokines in intestinal inflammation: pathophysiological and clinical considerations. Gastroenterology 1994; 106: 533-9.

2 Cohan VL, Scott AL, Dinarello CA, Prendergast RA. Interleukin-1 is a mucus secretagogue. Cell Immunol 1991; 136: 425-34.

3 Theodorou V, Eutamene H, Fioramonti J, Junien JL, Bueno $\mathrm{L}$. Interleukin-1 induces a neurally-mediated colonic secretion in rats: involvement of mast cells and prostaglandins. Gastroenterology 1994; 106: 1493-500.

4 Sutherland DB, Varilek GW, Neil GA. Identification and characterization of the rat intestinal epithelial cell (IEC18) interleukin-1 receptor. Am f Physiol 1994; 266: C1198-203.

5 Augeron C, Laboisse CL. Emergence of permanently differentiated cell clones in a human colonic cancer cell line in culture after treatment
Cancer Res 1984; 44: 3961-9.

6 Augeron C, Voisin T, Maoret JJ, Berthon B, Laburthe M, Laboisse CL. Neurotensin and neuromedin $N$ stimulate mucin output from human goblet cells (Cl.16E) via neurotensin receptors. Am $\mathcal{F}$ Physiol 1992; 262: G470-6.

7 Merlin D, Bou-Hanna C, Tien XY, Guo X, Laboisse CL, Hopfer U. ATP-stimulated electrolyte and mucin secretion in the human intestinal goblet cell line HT29-Cl.16E f Membrane Biol 1994; 134: 137-49.

8 Spriggs MK, Lioubin PJ, Slack J, Dower SK, Jonas U, Cosman D, et al. Induction of an interleukin-1 receptor (IL-1R) on monocytic cells. Evidence that the receptor is not encoded by a T cell-type IL-1R mRNA. $尹$ Biol Chem 1990; 265: 22499-505.

9 Sims JE, Gayle MA, Slack JL, Alderson MR, Bird TA, Giri JG, et al. Interleukin-1 signaling occurs exclusively via the 10 Forstner JF, Forstner GG. Gastrointestinal mucus. In Johnson LR, ed. Physiology of the gastrointestinal tract. 3rd ed. New York: Raven Press, 1994: 1255-84. 